\title{
Técnica para o estudo da anatomia da epiderme foliar de batata ${ }^{1}$
}

\author{
A technique for the anatomical study of potato leaf epidermis \\ Fernanda Bastos Segatto ${ }^{1}$ Dilson Antônio Bisognin ${ }^{2}$ Marlova Benedetti ${ }^{3}$ \\ Liege Camargo da Costa ${ }^{4}$ Marcos Vicente Rampelotto ${ }^{4}$ \\ Fernando Teixeira Nicoloso 5
}

- NOTA -

\section{RESUMO}

Embora a batata (Solanum tuberosum) seja uma espécie de grande valor econômico, são poucas as informações disponíveis sobre a anatomia foliar, principalmente de características estruturais da epiderme. O estudo da anatomia foliar assume grande importância básica, para a ecologia e fisiologia, e aplicada para a fitopatologia e o melhoramento genético. Este trabalho teve por objetivo identificar uma técnica histológica que permite a confecção de lâminas semipermanentes para avaliar a epiderme foliar, em vista frontal, de um grande número de plantas de batata em um curto período de tempo. O corte paradérmico a mão livre, o método de Jeffrey e as técnicas de hidróxido de potássio e de impressão da epiderme foram avaliados. Lâminas semipermanentes foram confeccionadas da secção frontal da epiderme de foliolos principais do terço médio de plantas de batata. A impressão da epiderme em lâmina foi a única técnica que possibilitou a avaliação adequada de todos os clones de batata utilizados. A impressão da epiderme é uma técnica muito rápida, de baixo custo e de fácil execução, que atende os requisitos necessários para a identificação e seleção de características anatômicas de um grande número de plantas em um programa de melhoramento genético de batata.
\end{abstract}

Palavras-chave: estômatos, pêlos, melhoramento, resistência.

\section{ABSTRACT}

Even though potato (Solanum tuberosum) is an economically important crop, information about leaf characteristics of anatomical structure has not been well studied. Studies of leaf epidermis have significance for basic fields as ecology and physiology and for applied fields as plant pathology and breeding. The objective of this research was to identify a fast and easy technique to prepare semipermanent slides for studying the anatomy of potato leaf epidermis. Para dermal free hand cut, Jeffrey method, potassium hydroxide and epidermal fingerprint on glass slide techniques were evaluated. Semi-permanent slides were prepared from the longitudinal section of main leaflets from the medium portion of potato plants. An adequate study of all evaluated clones was only possible with the epidermal fingerprint technique. The epidermal fingerprint on glass slides is a fast preparing, low cost and easy implementation technique, which enables to evaluate a high number of potato plants in a short period of time.

Key words: stomata, trichomes, breeding, resistance.

A batata cultivada (Solanum tuberosum) pertence à família Solanaceae. A batata é considerada a quarta cultura mais importante do mundo, sendo superada apenas pelo trigo, arroz e milho (ANONYMOUS, 1998). Embora seja uma espécie economicamente importante, são poucas as informações disponíveis na literatura referentes às descrições da anatomia foliar, no que diz respeito às características da epiderme, como espessura de cutícula, número, forma e localização dos estômatos e pêlos das diferentes variedades de batata. Resultados de anatomia foliar têm sido utilizados geralmente como

\footnotetext{
${ }^{1}$ Parte da Dissertação de Mestrado do primeiro autor apresentada ao Programa de Pós-graduação em Agronomia da Universidade Federal de Santa Maria (UFSM).

${ }^{2}$ Biólogo, Mestre em Agronomia, Departamento de Fitotecnia, UFSM.

${ }^{3}$ Engenheiro Agrônomo, PhD, Professor, Departamento de Fitotecnia, Camobi, UFSM, 97105-900, Santa Maria, RS. Email:dilsonb@smail.ufsm.br. Autor para correspondência.

${ }^{4}$ Engenheiro Agrônomo, Mestre em Agronomia, Departamento de Fitotecnia, UFSM.

${ }^{5}$ Acadêmico do Curso de Agronomia, UFSM, Bolsista da Fundação de Amparo a Pesquisa do Rio Grande do Sul (FAPERGS).

${ }^{6}$ Engenheiro Agrônomo, PhD, Professor, Departamento de Biologia, UFSM.
} 
subsídios para estudos de ecofisiologia, principalmente de balanço hídrico e capacidade fotossintética (GAVILANES, 1999). Estudos anatômicos assumem maior importância quando associados aos aspectos ecológicos, fisiológicos e comparativos, subsidiando trabalhos taxonômicos (METCALFE \& CHALK, 1979). Pela anatomia da epiderme foliar pode-se inferir sobre a absorção de nutrientes nas faces abaxial e adaxial, levando ao aumento da eficiência da aplicação foliar de nutrientes (LEECE, 1976; KANNAN, 1980). Também é importante identificar estruturas que atuam na resistência de plantas a patógenos para subsidiar estudos de fitopatologia e melhoramento genético.

O objetivo deste trabalho foi identificar uma técnica histológica que permite a confecção de lâminas semipermanentes para avaliar a epiderme foliar, em vista frontal, de um grande número de plantas de batata em um curto período de tempo.

Estudos da anatomia foliar de clones de batata foram realizados no Núcleo de Biotecnologia Aplicada à Produção Vegetal do Departamento de Fitotecnia da Universidade Federal de Santa Maria. Foram utilizados cinco clones de batata, sendo uma a espécie diplóide $(2 \mathrm{n}=2 \mathrm{x}=24) \boldsymbol{S}$. microdontum e os clones tetraplóides $(2 \mathrm{n}=4 \mathrm{x}=48)$ SMIH, SMII, SMIG274-3 e SMIJ461-1 avançados de melhoramento. As plantas de cada clone foram cultivadas em potes plásticos de $15 \mathrm{~cm}$ de diâmetro, contendo solo adubado, colocados sob telado coberto com plástico de $150 \mu \mathrm{m}$ de espessura. As lâminas semipermanentes foram preparadas a partir de material fresco localizado entre a nervura central e a borda de folíolos principais do terço médio das plantas, região onde estes se encontravam completamente expandidos, de uma planta por clone.

Foram avaliadas quatro técnicas de confecção de lâminas semipermanentes: 1) corte paradérmico à mão livre; 2) método de Jeffrey; 3 ) técnica de hidróxido de potássio; e 4) técnica de impressão da epiderme. $\mathrm{O}$ corte paradérmico à mão livre consiste em retirar a epiderme da folha com o auxílio de uma lâmina de aço (MACEDO, 1997). No método de Jeffrey, o mesófilo é dissolvido através da imersão em uma mistura constituída de partes iguais de ácido crômico a $10 \%$ e ácido nítrico a $10 \%$, por um período de 12 a 48h, visando isolar as epidermes foliares (JOHANSEN, 1940). A técnica de hidróxido de potássio consiste na dissociação das epidermes foliares, pela imersão em uma solução de hidróxido de potássio, com concentrações que variam de $1 \%$ a $3 \%$, e fervura, entre 10 e $30 \mathrm{~min}$, dependendo da textura do material a ser avaliado (MACEDO, 1997). A técnica de impressão da epiderme consiste em colocar uma gota de adesivo instantâneo universal (éster de cianoacrilato) sobre uma lâmina de vidro. A região de interesse do folíolo é então pressionada sobre a lâmina, por aproximadamente $10 \mathrm{~s}$, tempo necessário para que o adesivo se espalhe e seque o suficiente, permitindo a separação do folíolo da lâmina e a manutenção da impressão da epiderme.

Depois de confeccionadas, as lâminas foram mantidas em condições ambientais até a avaliação. Algumas lâminas foram então fotomicrografadas com o auxílio de um microscópio Olympus, modelo CH30RF200, utilizando-se filme Kodak® Ultra ISO 400, para ilustrações do material analisado.

\section{Corte paradérmico à mão livre}

A epiderme dos folíolos de batata se rompeu muito facilmente, por ser muito tênue, impossibilitando a sua retirada. O estudo da secção transversal de folíolos de plantas dos mesmos clones mostrou a presença de camada de células muito delgada, confirmando a baixa resistência da epiderme (dados não apresentados). O corte paradérmico à mão livre, apesar de seu baixo custo, é inviável para realizar estudos anatômicos da epiderme foliar de batata, apesar de ter sido utilizada com sucesso em espécies das famílias Arecaceae (LEITE \& SCATENA, 2001), Sterculiaceae (NAKAYAMA et al., 1996) e Pteridaceae (GRAÇANO et al., 2001).

\section{Método de Jeffrey}

A imersão dos folíolos na solução de ácido nítrico e crômico por três horas ainda não permitiu a separação das epidermes. A partir de seis horas de imersão, as bordas das epidermes desprenderam-se do mesofilo. Com 12 horas de imersão, as epidermes já apresentavam sinais de degradação, sendo que o mesofilo ainda se apresentava aderido à epiderme. Com 24 horas de imersão, as epidermes se apresentavam completamente degradadas, antes mesmo da dissolução das substâncias intercelulares. Isto impossibilitou a visualização das estruturas da epiderme de folíolos de batata, porém foi usada com sucesso em Gomphrena celosioides (Amaranthaceae) (GAVILANES, 1999).

Técnica de hidróxido de potássio

Os folíolos foram imersos na solução de concentração de $3 \%$ de hidróxido de potássio e 
submetidos à fervura por $10 \mathrm{~min}$, conforme recomendação da técnica (MACEDO, 1997). A fervura resultou na completa desintegração dos tecidos, inclusive das epidermes. Os folíolos imersos na solução de hidróxido de potássio na concentração de $1 \%$ mantiveram-se intactos após a fervura por $10 \mathrm{~min}$, porém no momento da separação manual das epidermes (com auxílio de lupa, agulha histológica e pincel) estas se romperam, impossibilitando a preparação das lâminas. $\mathrm{O}$ aumento do período de tempo de fervura ocasionou a degradação das epidermes antes da separação do mesofilo.

\section{Técnica da impressão da epiderme}

dentre as técnicas avaliadas, a impressão da epiderme foi a única que permitiu a obtenção de lâminas semipermanentes da epiderme de folíolos de todos os clones de batata analisados. Com esta técnica, uma pessoa pode confeccionar aproximadamente 20 lâminas por hora. A impressão da epiderme permitiu a visualização clara das diferentes estruturas da epiderme dos folíolos, como pêlos, estômatos, células epidérmicas comuns e células que recobrem as nervuras (Figura 1). Na face abaxial do clone SMIJ461-1, verificou-se a presença de estômatos, distribuídos de forma uniforme na superfície do folíolo, e de pêlos, próximos à nervura secundária. As células que recobrem a nervura puderam ser diferenciadas das células comuns da epiderme, pelo fato de estas células serem alongadas e orientadas no sentido longitudinal do segmento foliar. Uma melhor visualização das células comuns da epiderme e das células subsidiárias dos estômatos foi obtida em maior aumento (Figura 2A), mesmo em regiões do folíolo onde existiam pêlos (Figura 2B). Nos clones avaliados não foram observadas diferenças entre as células subsidiárias e as células comuns da epiderme, sendo os estômatos classificados morfologicamente como anomocítico e não anisocítico que é típico do gênero Solanum (FAHN, 1982). Diferenças de frequiência e de tamanho de pêlos entre e dentro do mesmo clone também puderam ser visualizadas (Figura 2B). A base dos pêlos está circundada por um conjunto de células epidérmicas que se dispõem de forma radial. Os pêlos destes clones são simples, unicelulares, não ramificados e do tipo não glandular (FAHN, 1982).

Dentre as técnicas estudadas, a de impressão da epiderme em lâmina foi a única que possibilitou a avaliação adequada de todos os clones de batata analisados. Permitiu observar claramente diferenças de freqüência de pêlos e estômatos e de tamanho de pêlos entre clones e faces do folíolo, podendo ser também usada para determinar os tipos de pêlos e estômatos presentes

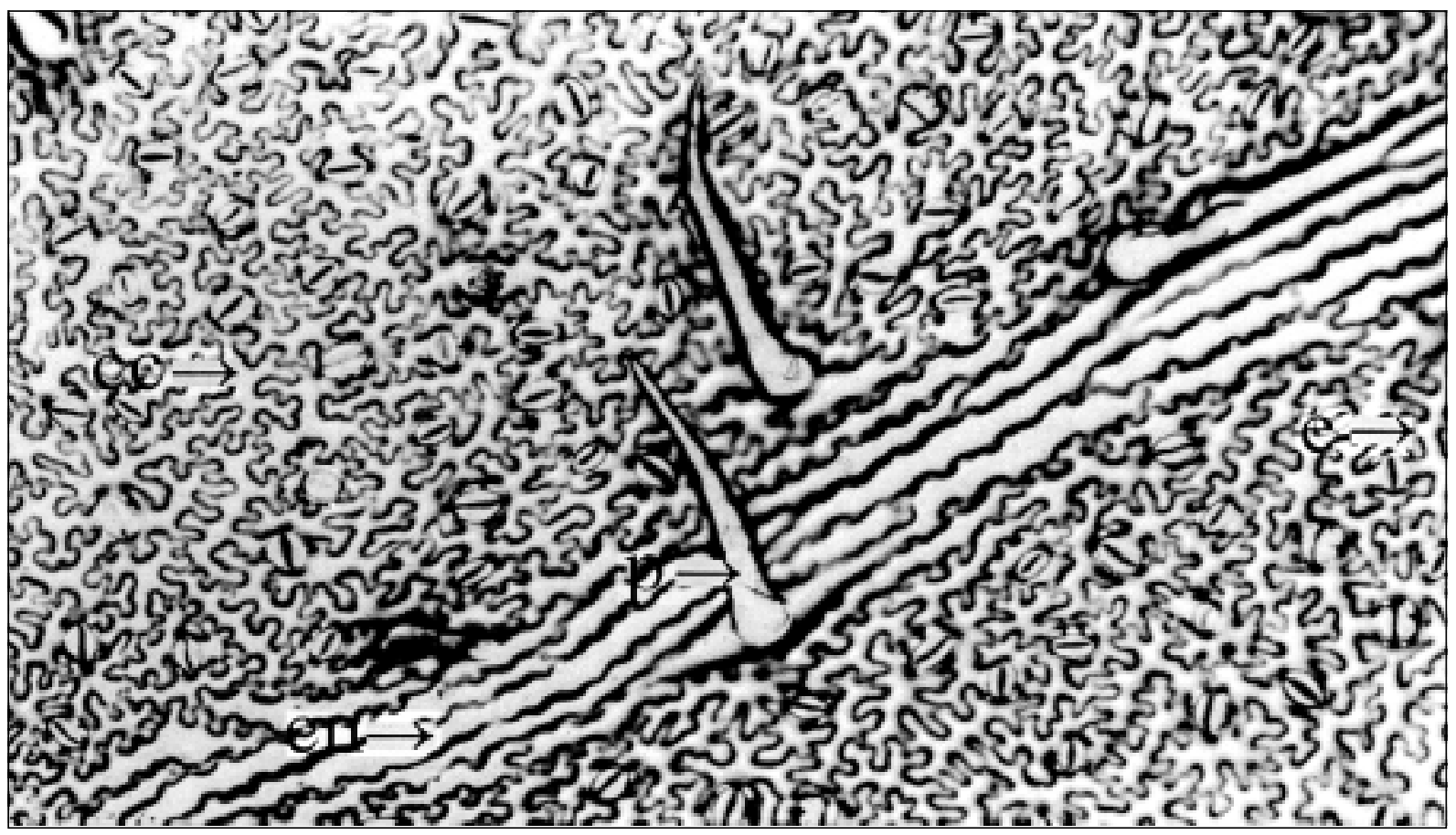

Figura 1 - Vista frontal da face abaxial (aumento 200x) de folíolo principal do clone SMIJ461-1 de batata. cc= célula comum da epiderme, $\mathrm{cn}=$ célula que recobre a nervura, $\mathrm{p}=$ pêlo, e= estômato. Santa Maria, RS, 2003.

Ciência Rural, v. 34, n.5, set-out, 2004. 


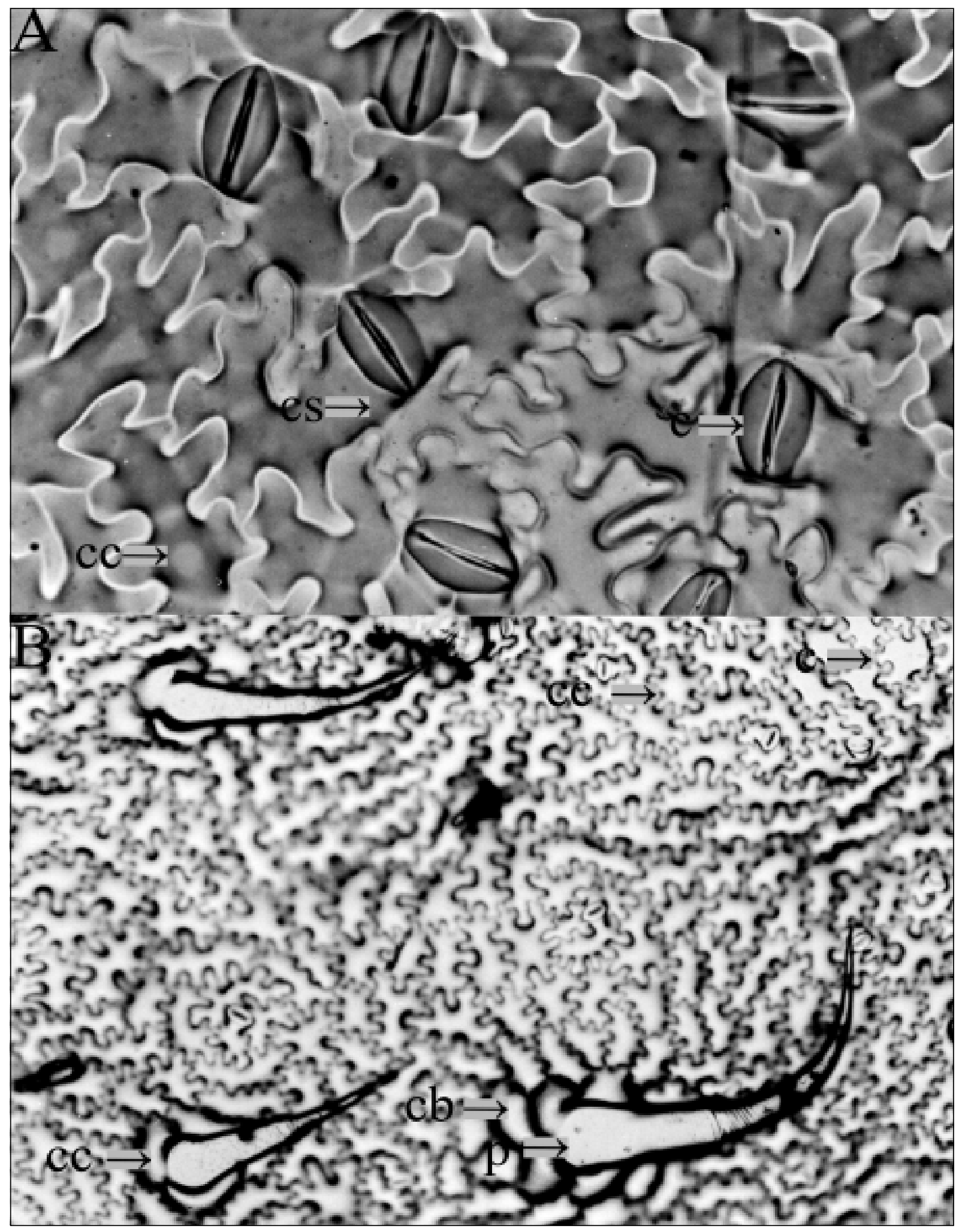

Figura 2 - Vista frontal da face abaxial (aumento 800x) de folíolo do clone SMII (A) e da face adaxial (aumento 200x) de folíolo do clone SMIH (B). cc= célula comum da epiderme, $c s=$ célula subsidiária do estômato, e= estômato, $c b=$ células da base do pêlo, p= pêlo. Santa Maria, RS, 2003.

Ciência Rural, v. 34, n.5, set-out, 2004. 
em diferentes clones de batata. Esta é uma técnica muito rápida, de baixo custo e de fácil execução, sendo que as lâminas semipermanentes podem ser mantidas em condições ambientais por um período superior a um ano, sem comprometer a qualidade de visualização. Portanto, a técnica da impressão da epiderme atende os requisitos necessários para a identificação e seleção de características anatômicas de um grande número de plantas em um programa de melhoramento genético de batata.

\section{REFERÊNCIAS BIBLIOGRÁFICAS}

ANONYMOUS. FAO production yearbook 1998. Rome: FAO Statistics Series, 1998, V.52.

FAHN, A. Plant anatomy. 3.ed. New York : Pergamon. 1982. 544p.

GAVILANES, M.L. Estudo anatômico do eixo vegetativo de plantas daninhas que ocorrem em Minas Gerais. I. Anatomia foliar de Gomphrena celosioidess Mart. (Amaranthaceae). Revista Ciência e Agrotecnologia, v.23, n.4, p.882-899, 1999.

GRAÇANO, D.; AZEVEDO, A.A.; PRADO, J. Anatomia foliar das espécies de Pteridaceae do Parque Estadual do Rio doce (PERD) - MG. Revista Brasileira de Botânica, v.24, n.3, p.333-347, 2001.
JOHANSEN, D.A. Plant microtechnique. New York : Mc Graw-Hill, 1940. 523p.

KANNAN, S. Mechanisms of foliar uptake of plant nutrients: accomplishments and prospects. Journal of Plant Nutrition, v.2, p.717-735, 1980 .

LEECE, D.R. Composition and ultrastructure of leaf cuticles from fruit trees, relative to differential foliar absorption. Australian Journal of Plant Physiology, v.3, n.6, p.833847, 1976.

LEITE, R.K.; SCATENA, V.L. Anatomia do segmento foliar de espécies de Syagrus Mart. (Arecaceae) da Chapada Diamantina, Bahia, Brasil. Sitientibus Série Ciências Biológicas, v.1, n.1, p.3-14, 2001.

MACEDO, N.A. Manual de técnicas em histologia vegetal. Feira de Santana : Universidade Estadual Feira de Santana, 1997. 96p.

METCALFE, C.R.; CHALK, L. Anatomy of the dicotyledons: leaves, stem and wood in relation to taxonomy with notes on economic uses. Oxoford : Clarendon, 1979. 276p.

NAKAYAMA, L.H.I.; SOARES, M.K.M.; APPEZZATO-DAGLÓRIA, B. Contribuição do estudo anatômico da folha e caule do cacaueiro (Theobroma cacao L.). Scientia Agrícola, v.53, n.1, p.73-80, 1996 